Georgia State University

ScholarWorks @ Georgia State University

Middle and Secondary Education Faculty

Publications

Department of Middle and Secondary Education

2006

\title{
Mentoring in Literacy Education: A Commentary from Graduate Students, Untenured Professors, and Tenured Professors
}

\author{
Mark B. Cobb \\ Dana L. Fox \\ Joyce E. Many \\ Georgia State University \\ Mona Matthews \\ Georgia State University \\ Ewa McGrail \\ Georgia State University
}

See next page for additional authors

Follow this and additional works at: https://scholarworks.gsu.edu/mse_facpub

Part of the Curriculum and Instruction Commons, and the Junior High, Intermediate, Middle School Education and Teaching Commons

\section{Recommended Citation}

Cobb, Mark B.; Fox, Dana L.; Many, Joyce E.; Matthews, Mona; McGrail, Ewa; Tinker Sachs, Gertrude; Taylor, Donna Lester; Wallace, Faith H.; and Wang, Yan, "Mentoring in Literacy Education: A Commentary from Graduate Students, Untenured Professors, and Tenured Professors" (2006). Middle and Secondary Education Faculty Publications. 107.

https://scholarworks.gsu.edu/mse_facpub/107

This Article is brought to you for free and open access by the Department of Middle and Secondary Education at ScholarWorks @ Georgia State University. It has been accepted for inclusion in Middle and Secondary Education Faculty Publications by an authorized administrator of ScholarWorks @ Georgia State University. For more information, please contact scholarworks@gsu.edu. 


\section{Authors}

Mark B. Cobb, Dana L. Fox, Joyce E. Many, Mona Matthews, Ewa McGrail, Gertrude Tinker Sachs, Donna Lester Taylor, Faith H. Wallace, and Yan Wang 
Mentoring in Literacy Education:

A Commentary from Graduate Students, Untenured Professors, and Tenured Professors

Mark Cobb, Dana L. Fox, Joyce E. Many, Ramona W. Matthews, Ewa McGrail, Gertrude Tinker Sachs, Donna Lester Taylor, Faith H. Wallace and Yan Wang

REVISED MANUSCRIPT: February 10, 2006

Running Head: Mentoring in Literacy Education 
Authors' Addresses:

Mark Cobb

Department of Early Childhood Education

Georgia State University

30 Pryor Street

Atlanta, GA 30303

Contact Person:

Dana L. Fox

Georgia State University

605 College of Education

30 Pryor Street

Atlanta, GA 30303

Phone: (404) 651-4050

Fax: (404) 651-2546

E-mail: dfox@gsu.edu

Joyce E. Many

Georgia State University

College of Education

30 Pryor Street

Atlanta, GA 30303

Ramona W. Matthews

Department of Early Childhood Education

Georgia State University

30 Pryor Street

Atlanta, GA 30303
Ewa McGrail

Georgia State University

College of Education

30 Pryor Street

Atlanta, GA 30303

Gertrude Tinker Sachs

Georgia State University

College of Education

30 Pryor Street

Atlanta, GA 30303

Donna Lester Taylor

Georgia State University

College of Education

30 Pryor Street

Atlanta, GA 30303

Faith H. Wallace

Secondary and Middle Grades Education

Bagwell College of Education

Kennesaw State University

1000 Chastain Road, \#0122

Kennesaw, GA. 30144-5591

Yan Wang

Georgia State University

College of Education

30 Pryor Street

Atlanta, GA 3030 


\begin{abstract}
This commentary continues a dialogue which began among literacy teacher educators attending an alternative format session about mentoring in the academy at a national conference. Literacy teacher educators participated in an informal discussion centered on the nature of mentoring in the academy for doctoral students, untenured professors, and tenured professors. Doctoral students focused on their changing identities and roles in the academy, their concerns about navigating the political infrastructure of academia, and the importance of assuming a proactive stance towards obtaining mentoring, especially for part-time doctoral students. Untenured professors focused on the ways they were inventing and reinventing themselves within the power and politics of academia and their need for more holistic mentoring during these turbulent times. Tenured professors were able to embed mentoring experiences into their scholarly work and find ways to benefit or learn from mentoring experiences. These mentors also found comfort in more informal mentoring that included self-initiated endeavors centered on mutual interests. Our commentary draws on these discussions as well as the professional literature on mentoring to describe the importance of mutual trust and reciprocity in mentoring throughout all stages of academia with attention to cultural and linguistic diversity.
\end{abstract}




\section{Mentoring in Literacy Education:}

A Commentary from Graduate Students, Untenured Professors, and Tenured Professors

Even though a large body of research exists on "mentoring" in general, only a small amount pertains to mentorship within the academy (e.g., Mullen, Cox, Boettcher, \& Adoue, 1997/2000). In the field of literacy education, knowledge about literacy teacher educators' perceptions of what constitutes successful mentoring relationships between faculty and graduate students is "virtually uncharted territory" (Alvermann \& Hruby, 2000, p. 46). In fact, Mullen and Cox (1997/2000) report that "little research has been undertaken on how mentoring relationships develop, endure, die, or change over time or on the impact of past mentoring on the actual relationships between mentors and neophytes" (p. xxi).

This commentary continues a dialogue which began among literacy teacher educators attending a session about mentoring in the academy at a national research conference. Because of the paucity of research on mentoring in literacy education and because of our own collective interest in mentoring within the academy, we conducted an alternative format session at the 2004 National Reading Conference (NRC) in San Antonio, Texas, USA. The purpose of this session was to elicit conversation and written reflection about the nature of mentoring that individuals had received or were receiving and the forms of mentoring they believed were needed in our field. After an initial introduction, several small groups were formed based on participants' levels of experiences and diverse needs. Groups consisted of students in doctoral programs, novice teacher educators, culturally diverse teacher educators, and tenured teacher educators. The small groups discussed (a) the types of mentoring received, (b) the strengths of the mentoring received, (c) the areas of current need of mentoring, and (d) the challenges to providing and receiving mentoring. Group members then presented their reflections to the whole 
group. This article represents our continuing reflections on what we learned from our discussion and dialogue in that session and from our review of mentoring research in literacy education and the broader academy.

In the sections that follow, we first provide a brief overview of the professional literature related to mentoring. We then explore mentoring in the lives of literacy teacher educators as we consider doctoral students', culturally diverse teacher educators', novice teacher educators', and tenured teacher educators' perspectives on mentoring.

Mentoring in the Academy

Traditionally, mentoring has been described as a relationship in which the mentor is perceived to possess more power and status than the mentee (Ervin \& Fox, 1994; Mullen \& Kealy, 2000). In the academy, mentoring opportunities have typically been discussed in terms of doctoral students' development in both formal (e.g., residency requirements, teaching and research apprenticeships) and informal ways (e.g., communication and interaction with faculty advisors who oversee doctoral students) (Golde \& Dore, 2001). In these so-called "informal” experiences, mentors provide guidance, support, and feedback to facilitate personal and career development to help novices learn about the culture of the academy and to expand opportunities for those traditionally hampered by social and institutional barriers. Some academics taking a critical stance view mentoring as a gendered (Chilly Collective, 1995; Ervin, 1994, 1995; Kirsch, 1993; Spore, Harrison, \& Haggerson, 2002), raced (Cole \& Barber, 2003; Moody, 2004; Turner \& Myers, 2000), or classed practice (Tokarczyk with Fay, 1993). In particular, scholars of color suggest that there is need for dialogue regarding how issues of gender, race, and class affect both mentees and mentors within institutions of higher education, and how we might transform the 
academy to overcome discrimination and marginalization (Lin, Grant, Kubota, Motha, Tinker Sachs, Vandrick, \& Wong, 2004).

Although traditional views of mentoring relationships in the academy have granted more power and status to the mentor, democratic approaches to mentoring are emerging, particularly in literacy education. Recently, research describing mentoring within literacy education has shown how the process of mentoring is being redefined. In one study, Young, Alvermann, Kaste, Henderson, and Many (2004) elaborated the important role that friendship can play in mentoring relationships between faculty and graduate students. In another study, Stansell (1997/2000) narrated his own personal development from graduate student to professor in literacy education, focusing on the role that mentors played in his journey. Other studies of mentoring in literacy education have looked closely at the process of academic writing and the role that mentoring plays in the dissertation process and the writing of qualitative research (Mullen, 1997/2000; Young \& Alvermann, 1997). In a self-study of their teaching of academic writing courses, Noll and Fox (2003) explored graduate students' perceptions of academic writing and what students believe mentors should do to support them in their writing of dissertations and articles for publication; as a result, they reported that they learned as much from the graduate students' comments and reflections as they did from the research and each other. In addition, other studies of mentoring in literacy education explore collaboration and the crucial role that support groups can play in mentoring for both graduate students as well as professors (Kong \& Pearson, 2005; Smith, Basmadjian, Kirell, \& Koziol, 2003; Wiseman, 1997/2000).

In the broader academy, a few new institutionalized programs for faculty development (e.g., Gaff, Pruitt-Logan, Sims, \& Denecke, 2003; Preparing Future Faculty, 2004; Sorcinelli, 2000; Yarger, Brittingham, Clark, Dolly, Galluzzo, Gideonse, Griggs, Harris, Howey, \& 
Sternberg, 1999) and professional standards for teacher educators (Association of Teacher Educators, 2004; Young, 2000) have also suggested more mutually satisfying forms of mentoring. These programs support what we know about how individuals learn, the socially constructed nature of learning, and the importance of experiential, situated learning where everyone is seen as capable of being both a mentor and a mentee.

Our stance toward mentoring certainly construes effective mentoring as that which is grounded by such constructivist understandings of learning. In fact, these constructivist perspectives of learning explain why as literacy teacher educators within a large urban university we hold the views we do of mentoring. The "demographic imperative" that Cochran-Smith (2004) speaks of is for us not a projection but a reality. To do the work we do with practicing and preservice teachers, we constantly seek ways to stimulate their development as teachers who are armed not only with knowledge of "best practice" in literacy teaching but also "alternative practice" (Cochran-Smith, 2004, p. 63). We must be mindful, however, that our own development as literacy teacher educators is as important as that of the preservice and inservice teachers with whom we work. As teacher educators, we must be involved in a process of reflection to examine ways in which our cultural lens has shaped our own view of the world.

To that end, we embrace a social reconstructionist view of teacher education (Cannella \& Reiff, 1994) and hence mentoring. This perspective when applied to mentoring purports that (a) each person has a unique reality; (b) reflection and examination of personal beliefs are essential; (c) involvement in cross-cultural experiences enhances understanding of ourselves and others; (d) we must examine our own cultural history in order to gain insights into our personal realities; and (e) institutions such as schools are guided by explicit and implicit beliefs that need examining. 
With the foregoing as context, next we share perspectives on mentoring described by doctoral students, culturally diverse students and faculty, faculty in their first years in the academy, and faculty after tenure and promotion. The review of the literature presented previously foregrounds some but not all of the characteristics of the mentoring experiences identified by those who joined in discussion at our conference session. Also evident in the different voices and needs of these subgroups is a desire for a broad and responsive view of mentoring that, among other possibilities, supports a social reconstructionist view.

Perspectives on Mentoring from Literacy Educators

\section{Doctoral Students' Perspectives on Mentoring: Donna and Mark}

At our alternative format session, we (Donna and Mark) facilitated the discussion among doctoral students focusing on mentoring experiences and needs. First, we individually listed and described ways in which mentors had worked with us; then, we worked together to reflect on the discussion. While individuals were focused on different aspects of mentoring, shared themes easily emerged.

We agreed that mentoring is an important part of any doctoral program. Indeed most of the activities of doctoral students can be considered opportunities for mentoring. For the members of our group, mentoring often occurred around work on the content of a class, assistantships, joint projects, and student writing assignments - activities leading up to the dissertation. Mentoring is not easily differentiated as an activity in itself; rather, it is one aspect of the relationships and interactions among persons. As doctoral students, we felt that our greatest mentoring experiences resulted from relationships that were friendly and relaxed (Young, et al., 2004). Three issues important to us as doctoral students focused on (1) our changing identities or roles, (2) learning about and navigating the politics inherent in the 
academy culture, and (3) assuming a proactive stance toward obtaining the kind of mentoring that we need as novice researchers/teacher educators.

Changing roles and identities. One striking characteristic of our experience as doctoral students was that our progress could not be characterized merely as the acquisition of knowledge and skills. At several points in our doctoral programs, we have found that stepping into new roles is required. As our roles quickly change, we often vacillate between confidence and insecurity. We are accustomed to being both teachers of children and students ourselves. As we begin to teach adults for the first time, we find that we are neither comfortable in the shoes as an expert nor in the role of a manager of adults in a classroom. We write articles and feel confident about our statements - until we receive critical reviews or when people ask questions about our published work. Thus, as doctoral students we struggle continually with new roles and emerging identities.

Effective mentors help us step into these new identities in several ways. Most of all, they treat us as peers. The relationship is not exactly between equals, as we often acknowledge their expertise and are subject to their evaluation. Still, they lead us to do our own thinking, with faith that we are fit to make the most of this guidance. They know how to ask questions that probe our thinking and are quick to note when they have learned something from us. Effective mentors also find ways to engage us in meaningful work. They arrange research and writing projects that are truly collaborative. They teach with us or work with us on our own teaching. They call on us as valued colleagues and valuable resources, creating a climate of mutual mentoring (Stansell, 1997/2000).

Understanding the politics and culture of academia. A second issue that emerged from our written reflections and discussions at the alternative format session was the importance of 
navigating within the culture of the university. As doctoral students unaccustomed to academic contexts, we expressed concern over the dangers of not understanding power structures and struggles within departments that have the potential to restrict our writing and our vision (Mullen et al., 1997/2000). Our most effective mentors carefully guide us through these murky waters through "a process of guided participation in cultural practices" (Kong \& Pearson, 2005, p. 226). Some of the doctoral students expressed appreciation for frank conversations with their mentors about the pros and cons of being a professor. One described the case of a mentor who warned of a backlash expected to result from the student's published position, and yet encouraged her to stand firm. We felt strongly that advantages naturally fall to full-time students who often tend to be more aware of departmental politics and of learning, mentoring, and employment opportunities, and who may know the faculty better than students who are not able to spend as much time on campus. Doctoral students can contribute to successful mentoring relationships by being self-monitoring, willing to share with others, and responsive to constructive criticism (Mullen, 2003, in press)

Assuming a proactive stance. Regardless of full- or part-time status, we agreed that it was up to doctoral students to seek relationships and projects with prospective mentors. Quality mentoring relationships need time to develop and represent a commitment on the part of both parties. In our experience, we have found that most professors are willing to work with doctoral students, but they tend to wait for the student to initiate these collaborations. Several rules of thumb surfaced about maintaining these relationships. E-mail seemed to be the preferred medium for keeping in touch with professors, as many perceive it to be less invasive as phone calls or unscheduled office visits. Doctoral students felt that it is essential that mentors can be counted on to reply in a timely manner and to be available in general. One student spoke highly of having 
regularly scheduled weekly meetings among a group of graduate teaching assistants and their mentor.

The mentoring experiences of doctoral students are varied. Some variation is accounted for by the full- and part-time difference noted previously. Another reason that experiences of doctoral students varied depended upon the degree to which the student takes the initiative in seeking mentors. Many doctoral students feel it is not their place to seek mentoring opportunities. This may be because they continue to think of themselves as students fulfilling the requirements of the system, rather than "preservice" professors preparing themselves for their profession. Successful doctoral students said that peers had sometimes expressed jealousy, interpreting the support they received to be a sign of favoritism or politics. Perhaps this is a form of capital gained from knowledge accrued from experience and should be shared with incoming doctoral students. Professors can also set more explicit policies about when and how they can be contacted and about what they might be willing to offer (Maher, Ford, \& Thompson, 2004).

Mentoring experiences are a valuable dimension of our doctoral process. Our mentors assist us as we adapt to our new identities and roles, and they help us navigate through the sometimes murky and uncharted doctoral process. Equally as important is our need to be proactive in seeking mentoring experiences. Finally, mentors can assist by setting explicit guidelines for when, how, and in what ways doctoral students can enter into these important mentoring opportunities.

\section{Cultural Perspectives on Mentoring: Gertrude and Yan}

Those who gathered to talk at the alternative format session about mentoring of diverse students and faculty were an all female group of four from different cultural backgrounds. The Afro-Caribbean, American Hispanic, and Mainland Chinese cultural roots of our group impacted 
the experiences of our group members in substantive ways. We were at different points in our academic careers: one a third-year professor (Yan), one beginning doctoral student, and two at the mid to advanced stages of our academic histories (including Gertrude). Although our group's expressed concerns overlapped with some themes from other groups, there were some perspectives that were unique to our group. The focus of conversation ranged from our experiences as doctoral students and then as professors. Most of our time, however, was spent discussing what could be done to provide culturally acceptable and mutually beneficial mentoring for international doctoral students and students from non-white and non-middle class backgrounds. From an intercultural perspective, we felt that the mentoring experiences described by group members could be categorized from superficial to deep, and we identified a number of attributes that characterized viable mentoring relationships.

Examining the depth of the mentoring experience. While members of our group had experienced a range of mentoring experiences, our written reflections and oral discussion showed that our mentors and mentoring varied considerably in the degree they supported our development. Some activities are best characterized as superficial experiences, defined as those experiences that assist you for the present time but do not help you become independent and stand on your own in the long run. One group member put it this way, "My professor helped me with my first presentation at the American Educational Research Association: He wrote the abstract, but I did not learn how to write an abstract myself." What this member reported is the need for deep learning; that is, learning for oneself with adequate support the first time so that he or she can do it alone the next time. Ultimately, all agreed, we need to learn to stand on our own. Through our writing and discussion in the conference session, we also identified experiences that involve more opportunities to begin to shoulder the responsibilities of academia, such as 
assisting with a job search, providing directions for accessing resources, and providing advice on publishing articles from [a] dissertation. A deep mentoring experience, on the other hand, we agreed, is one in which the mentor pushes for substantive learning and full student engagement in the acquisition of academic survival strategies. One group member reported, "My supervisor helped me organize myself, insisted on rigor even when I thought I was finished, and kept searching for new ways to interpret my data." In other words, the mentor modeled and supported deep learning by insisting on academic rigor.

Understanding attributes of effective intercultural mentoring. Throughout our discussion we noted that deep experiences are embedded in a healthy respect for the mentee as a person. In such relationships, the mentee may feel as an equal or feel encouraged because the supervisor made time to get to know [him/her] personally by taking [the mentee] out to dinner. For students coming from outside of the dominant culture, this aspect of getting to know the mentee is vital to developing a caring and supportive relationship. This includes acknowledging what the mentee can bring to the experience. During the conference session, a doctoral student from China who was new to the United States underscored this point by discussing that she lacked a supportive and personal relationship with her advisor. She articulated a desire for her advisor to recognize her culture but lamented, "She did not even have the interest to know." In many classes, one participant noted, international students are often the only ones from outside the dominant culture and sometimes this makes it difficult to form relationships. Another group member reported,

In a lot of classes, I was the only full-time student, and I was the only foreigner. I felt isolated from the native students, and there was no communication; there was a lack of sharing or exchange of information about jobs or anything. [I believed native U.S. 
students] also knew how to talk with the professor on an "equal footing" and shared knowledge that I was not privy to.

Although feelings of being isolated and alone are common for outsiders in the academy (Lin et al., 2004), all involved, insiders and outsiders alike, need to be proactive in finding ways to bridge the cultural divide.

Another aspect of mentoring that group members identified as particularly important for students not from the dominant culture was the need to collaborate with and be a part of a community with peers. One group member formed relationships outside of class with other international students and noted that they actually mentored each other. Every time one of the international doctoral students completed her or his oral exam, this group held a wine and cheese celebration. Being part of such a community not only provided emotional support and a sense of belonging but also helped those involved to deconstruct the process of an academic program and learn how to jump the hoops in the academy.

On the whole, this group felt that native students come into doctoral programs already possessing the discursive practices and a knowledge of "how to play the game" needed to survive in the academy, a knowledge that helps them negotiate with professors about where they want to go and how quickly they can get there. Such students have the edge when they share a cultural background with their professors. As Webb-Johnson (1997/2000) and Mullen (1997/2000) argue, outsiders must learn these discourses and learn how to negotiate them fluently. Moody (2004) speaks of this need, noting "an outsider in academia usually receives little or no mentoring, inside information, or introductions to valuable connections and networks" (p. 18). This problem is also closely connected with the lack of role models in the academy for people from non-majority ethnic groups (Tokarczyk with Fay, 1993). Majority, mainstream 
professors need to bear in mind what Greene (2001) says, "I often try to keep in mind the startling realization that those I hope to move to learn are not—and do not have to be- - versions of my White, studious, middle-class, urban, literary self" (p. 82).

While positive mentoring is critical for successful academic experiences, members of this group agreed that it is not the sole criterion for success in the academy. Other factors play critical roles, for example, one's personal attributes (such as motivation, inner strength, and willingness to take risks), the design and structure of an academic program, the supportiveness of the administration, and the collegial relationships available in an academic unit. While group members noted that the mentee is ultimately responsible for the development of positive and successful mentoring, we also discussed that this responsibility is culturally based. For instance, coming from a different class or cultural background, the mentee might apply a different set of rules when participating in academic activities or communicating with professors. This, in turn, might contribute to negative or ineffective mentoring experiences, especially if the mentor does not take the time needed to bridge the communication gap or the cultural divide. Moody (2004) reports how the academic field is "uneven" and how this "unevenness makes it difficult for majority faculty and their departments to appreciate the talents and strengths of non-majority [students and faculty]" (p. 1).

Even though mentoring has been described as "a slippery and provocative process" (Fish, 1993, p. 192) that takes place on an "uneven" academic field, we (Gertrude and Yan) believe that demystifying the process, as we are attempting to do in this article, is an important beginning toward more healthy mentoring experiences in graduate school and in the academy at large. Such practices and experiences can have a profound impact on building and maintaining student and 
faculty diversity in four-year colleges and universities in the United States (Cole \& Barber, 2003; Turner \& Myers, 2000).

\section{Perspectives on Mentoring from Academicians in Their First Years: Faith and Ewa}

How do I grow as a writer? How do I become part of a research community? How do I teach effectively? How do I work with others and make connections? When our (Faith and Ewa) group of first year literacy teacher educators discussed mentoring, participants asked these questions and more. At this point in their academic lives, these new faculty members said very little about who they are now or how they arrived there. Instead, their focus was on the future: Who will I become? How will I find my way? To that end, the new teacher educators in our group in the alternative format session talked about mentoring activities and experiences and the focus of these experiences in terms of their journey to invent themselves.

Inventing ourselves: Mentoring activities. Mentoring activities and experiences for these untenured professors involved them in seeking and taking advantage of support systems to gain an understanding of academia (e.g., tenure and promotion, advising, instruction, politics and culture). In some ways, the participants sought help from colleagues by asking for discussion meetings and e-mailing questions. In other ways, these new literacy educators took advantage of pre-set support systems such as attending new faculty classes or question-and-answer sessions. Additionally, some found support in social aspects from meeting with peers for lunch to learning vicariously through others' experiences. However, these experiences were not always positive, neutral, or free from the power and politics of academia. This was instantly apparent when one of our group members asked immediately after the session began, "Is this a safe environment?" This new faculty member feared that her comments and concerns might somehow "get back" to her department. 
Throughout our session, the experiences of these new literacy professors contained evidence of a culture of fear and power. For example, many were assigned a mentor, a situation that created a feeling of imposition and authority rather than friendship and nurturing. Some were specifically told what to do: what conference to attend, what activities to volunteer for (and what not to). Many feared the unknown and worried about potential failure in their new roles as educators and scholars. Socially, our group members felt that they learned what not to do by watching others and listening to the "gossip" around their departments.

The foci of these varied experiences were woven around the theme of invention of identity in the world of academia: institutional, personal, and sociocultural. Thus, untenured faculty voiced a need to discover who they are in terms of teaching, scholarship, and service. These participants talked about wanting to learn how to set up a research agenda, how to become part of a scholarly community, as well as how to balance both professional and personal lives. Group members were particularly interested in issues of power and politics - learning about who was in or not in power and uncovering the culture within the institution, as well as learning how to develop and maintain good relationships with colleagues and how to deal with personal conflicts over power and authority. Finally, the new faculty in our group valued personal stories as well as successful and unsuccessful models. Their reflection on these stories and models had the potential to provide answers to their burning questions and enabled them to invent themselves within academia.

Supporting our inventions. As the untenured faculty in our session looked to the future and imagined who they might become as literacy professionals, they called for sustained and personalized support in developing long-term professional goals in scholarship, teaching, and service as well as effective strategies for accomplishing these. We believe that modeling 
proactive thinking, time management, and self-monitoring, on the one hand, and providing constructive feedback for continued growth on the other, can facilitate these new faculty's efforts of professional identity construction.

These novice professors also emphasized the need for continued socialization into the academic world. They envisioned this process as learning about the culture, social norms, and power dynamics within the institution in a non-threatening and respectful environment. Only within such a nurturing environment, all agreed, can young faculty acquire both a strong personal voice, be recognized by other scholars, and contribute to a shared discourse within the scholarly and educational community to satisfy their equally strong desire for "belonging" to that social group. The following efforts can help new faculty in securing these needs: (1) self-selection of a mentor, to match mentee's and mentor's research interests and personal dynamics; (2) departmental coffee hours or brown-bag seminars, to create space for getting to know each other, to provide emotional support and encouragement, to share scholarship, and to develop plans for peer collaboration in all areas of professional activity; and finally, (3) thematic seminars, to develop interpersonal communication, conflict management, and power negotiation skills.

Like Mullen (1997/2000) and Mullen, Whatley, and Kealy (2000), our group of new faculty called for a holistic approach in meeting their complex needs in their first years in academia. Ideally, such an approach would treat each faculty as a whole person, addressing their intellectual, pedagogical, social, personal, and emotional needs collectively, rather than selectively attending only to intellectual needs (Smith et al., 2003). Thus, an ideal mentor for new faculty should cut across a spectrum of mentor types described as friend, career guide, information source, and intellectual guide (Sands, Parson, \& Duane, 1991, p. 189). Although it may seem a tall order, this holistic approach to mentoring must be undertaken so that new faculty 
not only can reinvent themselves as scholars and educators but also can internalize the discourse of academia, and thus, can learn both to function as members of that community and continue to grow as individuals.

Perspectives on Mentoring after Promotion and Tenure: Mona, Dana, and Joyce

In reviewing the professional literature, we found that scant attention has been given to the mentoring of those who have passed successfully through tenure and promotion (Alvermann \& Hruby, 2000). Many at this stage of their academic careers are involved in mentoring but they are generally mentors rather than mentees (e.g., Mullen \& Kealy, 2000). This is curious because several scholars such as Boyer (1990) and Frost and Taylor (1996) have discussed the different phases or rhythms professors experience during the course of their careers and the need for continued development during these progressions. From the discussion between the two associate and three full professors who formed a circle during the session at NRC to talk about their mentoring experiences, much was revealed. In fact, as tenured and promoted faculty, not only did we have valued experiences as mentors and mentees, we agreed that such experiences created a valued distraction from the added responsibilities many of us had assumed following tenure and promotion.

Earlier we discussed our belief in a social reconstructionist view of mentoring (Cannella \& Reiff, 1994). We borrow from the social constructivist roots of this view to describe the mentoring of these experienced faculty members. Context, action, and mediation, constructs rooted in a sociocultural paradigm, provide a frame for understanding our mentoring experiences. Figure 1 illustrates the characteristics of the contexts of the experiences, the actions of those involved, the means by which these actions are mediated, and the forces created from the convergence of these characteristics. The combined effect of these forces produces 
professional synergy (Mullen, 2000; Mullen \& Lick, 1999). A brief discussion of the process depicted in the figure follows.

Insert Figure 1 about here

Understanding the role of context in mentoring. From a sociocultural perspective, context is a dual concept signifying the physical boundaries of an event as well the values held by the context's creator (Wells, 1999). Physically, the contexts within which the tenured professors' mentoring experiences occurred were removed from the university. These experiences were informal and personally created and provided opportunities to focus on individual professional endeavors. For example, two tenured professors, who work at the same university but in different departments, talked about their monthly lunches away from the university in which they discussed their individual research and writing projects. Another shared how she and her writing partners often worked together in places other than their respective offices or homes, sometimes even traveling miles away for an uninterrupted weekend of thinking and writing. Group members spoke of how such separations from institutional contexts freed them to focus on personal work without the intrusion of the responsibilities and realities of both university and personal lives.

The more relaxed, informal physical spaces in which these experienced professors met made it possible for them to talk about work in ways that were relaxed and informal. As such the work shared did not need to be polished, but could be a draft or even thoughts and ideas about a future project. Thus, the physical spaces represented the casual intent of those involved and reflected how their social and professional lives merged (Cannella \& Reiff, 1994). As Figure 1 illustrates, these characteristics (i.e., not institutionally defined, informal, and personally created) enabled the group members to align their thoughts, interests, and attention on their personal 
work. This informal, self-selected context created an environment for discussion that was often not possible when they returned to the physical setting of the university.

Understanding the role of action in mentoring. From a sociocultural perspective, action represents not only the behavior of individuals but the ultimate reason or goal that brought the individuals together and thus reveals the meaning of that event (Wertsch, 1991). As experienced faculty, those gathered to talk in this group generally agreed that at this point in their professional lives, they were able to define their own goals. Further, they also selected, sought, and nurtured those interactions which were in accord with these goals. These interactions were reciprocal, self-initiated, and recursive, the same characteristics others have found in successful mentoring experiences (e.g., Mullen, 2000; Portner, 2002)

Reciprocity, a construct noted in some mentoring research (e.g., Mullen et al., 1997/2000; Young, et al., 2004), describes the experiences of those gathered to talk at this session. For example, the tenured professors spoke of how their mentoring of novice writers in their roles as editors or members of editorial boards had made them better writers themselves. One related how designing course experiences to mentor graduate students in academic writing brought clarity to her own thinking about such writing (Noll \& Fox, 2003). These experiences were performed within roles these members selected and nurtured for themselves as individuals. They accepted the role as editor or said "yes" when invited to join an editorial board. They designed courses around topics of personal interest realizing that they stood to gain as much from the experience as they hoped to provide for others. Consequently, these experienced faculty chose to interact in ways and in roles that would assist others while at the same time nurturing their own professional development. 
In addition to being reciprocal, the mentoring activities of these experienced faculty were self-initiated and as much about creating opportunities just to get together as they were about gaining insights that would further their individual work. Strategies initiated by those present, reflecting similar views in the field (Wiseman, 1997/2000; Mullen, in press), included creating book study groups, collaborating on research projects, and co-presenting at professional conferences.

The mentoring experiences of the tenured faculty also were recursive. The time spent in these co-mentoring relationships created a history that enabled tenured professors to understand the chronology of that work. This gave experienced faculty a unique vantage point to view each other's work and provided insights to which others might not be privy. Participants spoke of how being able to clarify their thinking during these conversations enabled them to see how their thinking had developed across time. More importantly, ongoing relationships allowed for discussions of how current projects connected to broader, long-term goals that these individuals had set for themselves as researchers and writers.

As illustrated in Figure 1, these actions, which are best described as reciprocal, selfinitiated, and recursive, provided momentum to move these experienced faculty forward in their thinking about their work as researchers and writers. Moreover, such a momentum was needed because the heavier responsibilities they assumed as experienced faculty and mentors often detracted from the energy and focus they needed to fulfill their personal professional goals.

Understanding the role of mediation in mentoring. From a sociocultural perspective, tools and symbols with language, often referred to as the "tool of tools," mediate actions. The aspect of mediation useful for this group, however, was not so much the language used during their mentoring experiences; rather, it was what made these conversations possible. The 
mentoring experiences of this group were shaped and molded through social interactions, avenues of choice, and mutual interests.

As these tenured professors discussed their mentoring experiences, it became apparent that the social benefits of such experiences were viewed as more important than the professional ones. One spoke of taking walks with a colleague, which resulted in their planning a project in which they could work together. The lunches regularly scheduled by two other experienced faculty members began with discussions of family. Although professional topics were discussed during such experiences, the professional benefits often seemed to be secondary to the social benefits. Friendships developed built on trust, a trust that these individuals asserted enabled them to take risks with new ideas, unfinished drafts, and explorations of long-term professional goals. Trust and friendships, characteristics others have discussed as key in mentoring relationships (Alvermann \& Hruby, 2000; Young, et al., 2004) also appeared to be a consequence of this group's experiences.

Because these actions were self-initiated and the contexts in which they occurred were personally created, they were mediated by avenues of choice. As individuals who had passed through tenure and promotion, they were not encumbered by the concerns expressed by doctoral students or the worries noted by those in the beginning years of their academic careers. Left unencumbered by such concerns, they were free to choose both with whom they would interact and the venues for these interactions.

Mutual interests also mediated their interactions. The tenured professors in our session agreed that over time their mentoring experiences led to the development of a mutual interest in each other's work. This shared interest freed the participants in these co-mentoring relationships to discuss both personal and professional issues. As one member noted, "I can call a meeting just 
because I need to talk." Further, one member noted that during these meetings, she could discuss her work without feeling that she was imposing or that she would be viewed as bragging, or worse that she would be perceived as inadequate. Consequently, all discussed how such meetings energized them and left them with a clarified sense of their individual and collective work and goals, often with new ideas to ponder.

As we reflected on the mentoring experiences of our group of experienced faculty members, much was revealed. We had a clearer sense of the nature of the contexts within which mentoring occurred for these individuals and how these contexts served to align their focus on their professional lives. Also revealed was how interactions within these settings provided much needed momentum as participants attempted to carve out time to devote to their lives as researchers and writers. We also came to understand that the interactions that transpired occurred via social interactions, avenues of personal choice, and mutual interests. These combined to energize participants' thinking and their efforts to focus on their work.

Figure 1 depicts the ultimate effect of these mentoring experiences - professional synergy, a synergy that resulted from the confluence of what this group of experienced faculty valued - personal relationships, choice with whom and where they interact, and the freedom to pursue goals they define. Mullen (2000) and Mullen and Lick (1999) discuss the importance of synergy in the university school partnerships and study groups when the mentor and mentees combined their efforts to work toward common goals. All participants benefited from this collaboration. Our reference to professional synergy illustrates the effect these mentoring experiences had on our personal and professional growth. Although our mentoring experiences were social in nature, the informal contexts aligned our behavior, the reciprocal and recursive 
action promoted momentum for our career, and the meditation across our social interactions created energy. Each of these elements converged to impact us individually.

Concluding Thoughts

Clearly, mentoring is an activity that is vitally important to literacy teacher educators across our careers, from the doctoral program to the beginning of the professoriate, through and beyond promotion and tenure. As we reflect on our own experiences as mentors and mentees, on our conversations about mentoring with others at the conference session, and on our review of the literature related to mentoring, we have learned that even though mentoring experiences and needs change over time, the need for mentoring relationships - especially those that are characterized by mutual trust and reciprocity—does not diminish across the span of an academic career (Mullen et al., 1997/2000). In addition, embedded throughout this career span are issues related to cultural and linguistic diversity, issues which we believe must be interrogated continually as well as embraced by mentors within the academy. As Merryfield (2001) suggests, all academicians must journey toward developing a sense of "global competence," and in their work as mentors, they should become more culturally attuned as they strive for more effective and mutually satisfying ways of working with others who are different from themselves. Such mentoring relationships, argue Mullen and Cox (1997/2000), “can . . gradually transform forces of repression that operate within restrictive educational settings" such as higher education (p. Xviii).

To that end, we trust that our reflections described herein will encourage those who are doctoral students as well as novice and experienced professors to reflect upon, share, and critique their experiences of being mentored and of mentoring. As literacy researchers and teacher educators, we believe that we need more critical narratives concerning the diverse experiences 
and perspectives on mentoring that exist, particularly in our field. Such stories may help us continue to envision and enact the types of reciprocal mentoring relationships we value and to co-create new forms of mentoring for all. 


\section{References}

Alvermann, D.E., \& Hruby, G.G. (2000). Mentoring and reporting research: A concern for aesthetics. Reading Research Quarterly, 35 (1), 46-63.

Association of Teacher Educators. (2004). Standards for teacher educators. Retrieved November 23, 2004, from http://www.ate1.org/pubs/Standards_for_Teac.cfm

Boyer, E. L. (1990). Scholarship reconsidered: Priorities of the professoriate. San Francisco: Jossey-Bass.

Cannella, G. S. \& Reiff, J. C. (1994). Preparing teachers for cultural diversity: Constructivist orientations. Action in Teacher Education, 16 (3), 37-45.

Chilly Collective, The. (Eds.). (1995). Breaking anonymity: The chilly climate for women faculty. Waterloo, Canada: Wilfrid Laurier University Press.

Cochran-Smith, M. (2004). Walking the road: Race, diversity, and social justice in teacher education. New York: Teachers College Press.

Cole, S., \& Barber, E. (2003). Increasing faculty diversity: The occupational choices of highachieving minority students. Cambridge, MA: Harvard University Press.

Ervin, E. (1994). Mentoring recomposed: A study of gender, history, and the discourses of education. Unpublished doctoral dissertation, University of Arizona, Tucson.

Ervin, E. (1995). Power, frustration, and "fierce negotiation" in mentoring relationships: Four women tell their stories. Women's Studies, 24, 445-481.

Ervin, E. \& Fox, D.L. (1994). Collaboration as political action. Journal of Advanced Composition, 14 (1), 53-71.

Fish, C. (1993). "Someone to watch over me": Politics and paradoxes in academic mentoring. In M. M. Tokarczyk with E. A. Fay (Ed.), Working-class women in the academy: Laborers 
in the knowledge factory ( pp.179-196). Amherst, MA: University of Massachusetts Press.

Frost, P. J., \& Taylor, M. S. (Eds.). (1996). Rhythms of academic life. Personal accounts of careers in academia. Thousand Oaks, CA: Sage.

Gaff, J.G., Pruitt-Logan, A.S., Sims, L.B., \& Denecke, D.D. (2003). Preparing future faculty in the humanities and social sciences: A guide for change. Washington, DC: Council of Graduate Schools and the Association of American Colleges and Universities. Retrieved November 23, 2004, from http://www.preparing-faculty.org/PFFWeb.PFF4Manual.pdf

Golde, C. \& Dore, T. (2001). At cross purposes: What the experiences of today's doctoral students reveal about doctoral education. Pew Charitable Trusts Survey. Retrieved November 23, 2004, from http://www.pewtrusts.com/pdf/edu_cross_purpose.pdf

Greene, M. (2001). Reflections on teaching. In V. Richardson (Ed.), Handbook of research on teaching (4th ed.), (pp. 82-89). Washington, DC: AERA.

Kirsch, G.E. (1993). Women writing the academy: Audience, authority and transformation. Carbondale, IL: Southern Illinois Press and Urbana, IL: National Council of Teachers of English.

Kong, A., \& Pearson, D. (2005). Learning: A process of enculturation into the community’s practices. Research in the Teaching of English, 39, 226-230.

Lin, A., Grant, R., Kubota, R., Motha, S., Tinker Sachs, G., Vandrick, S., \& Wong, S. (2004). Women faculty of color in TESOL: Theorizing our lived experiences. TESOL Quarterly, 38 (3), 487-504. 
Maher, M., Ford, M., \& Thompson, C. (2004). Degree progress of women doctoral students: Factors that constrain, facilitate, and differentiate. The Review of Higher Education, 27, 384-408.

Merryfield, M.M. (2001). Implications of globalization for teacher education in the United States: Towards a framework for globally competent teacher educators. $53^{\text {rd }}$ Annual Meeting of American Association of Colleges for Teacher Education, Dallas, TX.

Moody, J. (2004). Faculty diversity: Problems and solutions. New York: Routledge Falmer.

Mullen, C.A. (1997/2000). Post-sharkdom: An alternative form of mentoring for teacher educators. In C.A. Mullen, M.D. Cox, C.K. Boettcher, \& D.S. Adoue (Eds.), Breaking the circle of one: Redefining mentorship in the lives and writings of educators (pp. 145174). New York: Peter Lang.

Mullen, C.A. (in press). Naturally occurring student-faculty mentoring relationships: A literature review. In T.D. Allen \& L.T. Eby (Eds.), Blackwell handbook of mentoring: A multiple perspectives approach. Malden, MA: Blackwell Publishing.

Mullen, C.A. (2003). The WIT cohort: A case study of informal doctoral mentoring. Journal of Further and Higher Education, 27, 411-426.

Mullen, C. A. (2000). Constructing co-mentoring partnerships: Walkways we must travel. Theory and Practice, 39 (1), 4-11.

Mullen, C.A., with Cox, M.D. (1997/2000). Preface: Breaking the circle of one through mentorship. In C.A. Mullen, M.D. Cox, C.K. Boettcher, \& D.S. Adoue (Eds.), Breaking the circle of one: Redefining mentorship in the lives and writings of educators (pp. xvxxiii). New York: Peter Lang. 
Mullen, C.A., with Cox, M.D., Boettcher, C.K., \& Adoue, D.S. (Eds.). (1997/2000). Breaking the circle of one: Redefining mentorship in the lives and writings of educators. New York: Peter Lang.

Mullen, C.A., \& Kealy, W.A. (2000). Opportune encounters: Hosting extramural mentoring programmes for new scholars. Mentoring and Tutoring, 8 (3), 221-240.

Mullen, C.A., Whatley, A., \& Kealy, W.A. (2000). Widening the circle: Faculty-student support groups as innovative practice in higher education. Interchange: A Quarterly Review of Education, 31 (1), 35-60.

Mullen, C.A., \& Lick, D.W. (2005) New directions in mentoring: Creating a culture of synergy. New York: Routledge.

Noll, E., \& Fox, D.L. (2003). Supporting beginning writers of research: Mentoring graduate students' entry into academic discourse communities. In C.M. Fairbanks, J. Worthy, B. Maloch, J.V. Hoffman, \& D. Schallert, (Eds.), 52 ${ }^{\text {nd }}$ Yearbook of the National Reading Conference (pp. 332-344). Chicago: National Reading Conference.

Portner, H. (2002). Being mentored: A guide for protégés. Thousand Oaks, CA: Crown Press. Preparing Future Faculty. (2004). Preparing future faculty: Web overview. Washington, DC: Council of Graduate Schools. Retrieved November 23, 2004, from www.preparing-faculty.org

Sands, R. G., Parson, L. A., \& Duane, J. (1991). Faculty mentoring faculty in a public university. The Journal of Higher Education, 62, 174-193.

Smith, E.R., Basmadjian, K.G., Kirell, L., \& Koziol, S.M. (2003). On learning to teach English teachers: A textured portrait of mentoring. English Education, 36 (1), 6- 34. 
Sorcinelli, M.D. (2000). Principles of good practice: Supporting early-career faculty.

Washington, DC: American Association for Higher Education. Retrieved November 23, 2004, from http://www.aahe.org/ffrr/principles_brochure2.htm

Spore, M.B., Harrison, M.D., \& Haggerson, N. L. (2002). Stories of the academy: Learning from the good mother. New York: Peter Lang.

Stansell, J.C. (1997/2000). Mentors and mentoring: Reflections of a circle with/in circles. In C.A. Mullen, M.D. Cox, C.K. Boettcher, \& D.S. Adoue (Eds.), Breaking the circle of one: Redefining mentorship in the lives and writings of educators (pp. 121-144). New York: Peter Lang.

Tokarczyk, M.M., with Fay, E. A. (Ed.). (1993). Working class women in the academy: Laborers in the knowledge factory. Amherst: University of Massachusetts Press.

Turner, C. S.V., \& Myers, S. L.. (2000). Faculty of color in academe: Bittersweet success. Needham Heights, MA: Allyn \& Bacon.

Webb-Johnson, G. (1997/2000). My emerging destiny: Mentoring from an African-American perspective. In C.A. Mullen, M.D. Cox, C.K. Boettcher, \& D.S. Adoue (Eds.), Breaking the circle of one: Redefining mentorship in the lives and writings of educators (pp. 3-19). New York: Peter Lang.

Wells, G. (1999). Dialogic inquiry: Toward a sociocultural practice and theory of education. Cambridge, England: Cambridge University Press.

Werstch, J.V. (1991). Voices of the mind: A sociocultural approach to mediated action. Cambridge, MA: First Harvard University Press.

Wiseman, D.L. (1997/2000). Patterns of mentoring: Weaving teacher educators' career stories. In C.A. Mullen, M.D. Cox, C.K. Boettcher, \& D.S. Adoue (Eds.), Breaking the circle of 
one: Redefining mentorship in the lives and writings of educators (pp. 189-199). New York: Peter Lang.

Yarger, S., Brittingham, B., Clark, V.L., Dolly, J., Galluzzo, G., Gideonse, H., Griggs, M.B., Harris, M., Howey, K., Sternberg, L. (1999). The next generation of teacher educators: Preparing the professoriate. A report by the Task Force on Education of the Professoriate prepared for the Association of Colleges and Schools of Education in Land Grant Colleges and State Universities and Affiliated Private Universities.

Young, J.P., \& Alvermann, D.E. (1997). The making of a researcher: A self-study of a mentoring relationship. In K. Camperell, B. Hayes, \& R. Telfer (Eds.), $17^{\text {th }}$ Yearbook of the American Reading Forum (pp. 113-125). Logan, UT: Utah State University.

Young, J.P., Alvermann, D.E., Kaste, J., Henderson, S., \& Many, J. (2004). Being a friend and a mentor at the same time: A pooled case comparison. Mentoring and Tutoring, 12 (1), 2336.

Young, M. (2000). Preparing English teacher educators: Defining a process. English Education, $32(5), 226-236$. 
Figure 1

Mentoring beyond promotion and tenure: A convergence of elements to affect professional synergy

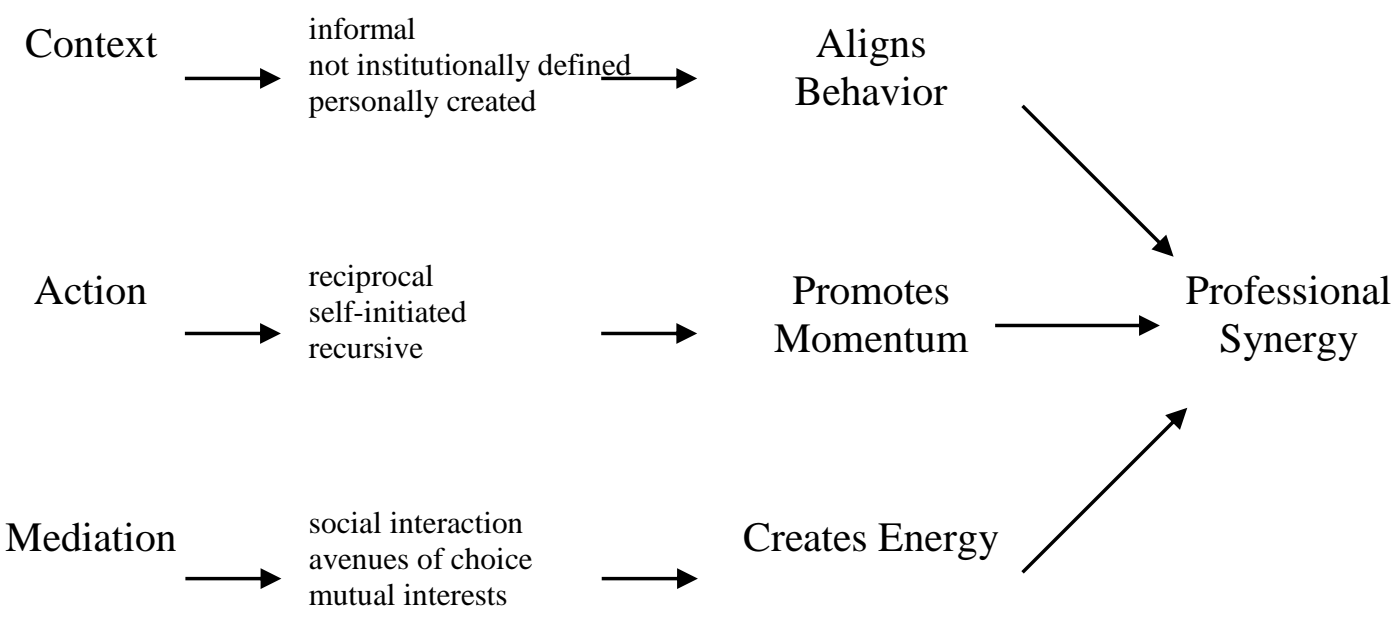

